\title{
Characterization of the Fetal Glucose Transporter in Rabbit Kidney Comparison with the Adult Brush Border Electrogenic $\mathrm{Na}^{+}$-Glucose Symporter
}

\author{
Jeanne C. Beck, Michael S. Lipkowitz, and Ruth G. Abramson \\ Department of Medicine, Mount Sinai School of Medicine, New York, New York 10029
}

\begin{abstract}
Glucose transport was characterized in rabbit renal brush border membrane vesicles (BBMV) of the fetus late in gestation. Highly purified, osmotically reactive fêtal BBMV contained a glucose transporter that was qualitatively indistinguishable from that in the adult: both are concentrative, $\mathrm{Na}^{+}$ dependent, èlectrogenic, stereospecific, and sensitive to phlorizin. Although the apparent $K_{m}$ for glucose is similar in the fetus and adult, the $V_{\max }$ is significantly higher in the adult. When the membrane potential was clamped with a protonophore, this difference diminished; however, $V_{\max }$ remained significantly higher in adult BBMV. This postnatal increase in $V_{\max }$ was paralleled by a similar increase in the number of phlorizin binding sites. These findings indicate that the maturational increase in glucose transport is, in part, consequent to a more favorable electrical potential for $\mathrm{Na}^{+}$-dependent glucose transport and, in part, the result of the insertion of new transporters. The homogenate activity of several brush border enzymes also demonstrated significant maturational increases. The magnitude of these changes was variable and enzyme dependent. These combined observations suggest that mature expression of membrane proteins (transporters and enzymes) occurs at different stages of development of renal proximal tubule cells.
\end{abstract}

\section{Introduction}

The ability of the fetal kidney to reabsorb glucose has been demonstrated in rats (1), guinea pigs (2), pigs (3), and lambs (4, 5). Indeed, glucose reabsorption has been reported in the fetus by the middle of gestation (4). Studies using cortical slices of fetal rat kidney late in gestation have demonstrated that the kidney's reabsorptive capacity for glucose increases from day 18 to day 21 of gestation (term $=21 \mathrm{~d}$ ) as evidenced by an increase in the intracellular/extracellular ratio of alpha-methylglucoside, a nonmetabolizable analogue of glucose (1). This reabsorption appears to be $\mathrm{Na}^{+}$dependent (1), and a reduction in glucose reabsorption has been observed after administration

Address reprint requests to Dr. Jeanne C. Beck, Division of Nephrology, Department of Medicine, Mount Sinai Hospital, Annenberg Building, Room 23-38, 100th Street and Fifth Avenue, New York, NY 10029.

Portions of this work were presented at the 20th Annual Meeting of the American Society of Nephrology, Washington, DC, December 1987.

Received for publication 16 Jantuary 1987 and in revised form 29 February 1988.

J. Clin. Invest.

(c) The American Society for Clinical Investigation, Inc.

0021-9738/88/08/0379/09 \$2.00

Volume 82, August 1988, 379-387 of phlorizin, an inhibitor of $\mathrm{Na}^{+}$-dependent glucose transport (4).

In adult animals, D-glucose is reabsorbed by the kidney at the luminal surface of the proximal convoluted tubule by a process that is saturable, stereospecific, inhibited by phlorizin, $\mathrm{Na}^{+}$dependent, and electrogenic $(6,7)$. Although it has been suggested that it is this specific glucose transport system that is developing in the fetus, this conclusion is not definitive. It is not known whether the increase in glucose reabsorptive capacity is related to acquisition of new nephron units, maturational increases in the surface area for reabsorption, enhanced $\mathrm{Na}^{+}$ pump activity in the basolateral membrane, or developmental changes in the glucose transporter per se. Interpretation of these experiments is further complicated by the fact that both clearance studies $(2,5)$ and cortical slice $(1)$ techniques measure simultaneous transport across both the brush border and basolateral surfaces in the intact proximal cell. This precludes a detailed description of events at one epithelial surface independent of the rate of efflux at the opposite surface or the driving force generated by the $\mathrm{Na}^{+}$pump in the antiluminal membrane. Certainly, in studies of development in which there is an elaboration of both membrane surfaces, it is difficult to use these techniques to distinguish developmental changes in brush border $\mathrm{Na}^{+}$-dependent glucose transporters from the generation of a more favorable electrochemical gradient for transport as a consequence of the development of additional basolateral $\mathrm{Na}^{+}$pumps. The use of isolated brush border membrane vesicles (BBMV) ${ }^{1}$ obviates these problems. Further, this preparation allows one to approach directly the $\mathrm{Na}^{+}$-dependent glucose carrier and to determine mechanisms of development independent of changes in membrane surface area and alterations in energy metabolism.

The current study was designed with the following objectives: $(a)$ to isolate BBMV from fetal kidneys, $(b)$ to assess the functional integrity of these structures, $(c)$ to characterize the glucose transport system in the fetal BBMV, and (d) to compare the glucose transport system present in the fetus with that of the adult. The data obtained indicate that the transport of glucose into osmotically active fetal BBMV is an uphill, electrogenic, stereospecific process that is also sensitive to phlorizin. The only apparent differences between the fetal and adult glucose transport systems are in the magnitude of concentrative transport and maximal rate of transport $\left(V_{\max }\right)$. These studies demonstrate that the increase in $V_{\max }$ that occurs during maturation is consequent to both a change in membrane permeability that favors $\mathrm{Na}^{+}$-glucose transport and the insertion of additional $\mathrm{Na}^{+}$-glucose transporters.

1. Abbreviations used in this paper: BBMV, brush border membrane vesicles; DPH, 1,6-diphenyl-1,3,5-hexatriene; FCCP, carbonyl cyanide $p$-trifluoromethoxyphenyl-hydrazone; G, conductance; $N_{0}$, concentration of receptor sites; $\mathrm{PD}$, potential difference. 


\section{Methods}

\section{Membrane isolation}

Gravid New Zealand white rabbits were obtained from a local supplier (Bunnyville, Littlestown, PA) at least $3 \mathrm{~d}$ before use. At $28 \mathrm{~d}$ in gestation $($ term $=31 \mathrm{~d})$, the doe was killed and the fetuses were delivered. No distinction was made regarding the sex of the fetuses. Three litters were used for each experiment. Control adult kidneys were obtained from the doe or a nonpregnant female of comparable age and weight. The fetal and adult kidneys were removed, weighed, chilled in $300 \mathrm{mM}$ mannitol, $10 \mathrm{mM}$ Tris, and $16 \mathrm{mM}$ Hepes, $\mathrm{pH} 7.5$, and the cortices were dissected and homogenized. BBMV were isolated by the $\mathrm{Mg}^{2+}$ aggregation method of Booth and Kenny (8) with the modifications of Aronson (9). Purified membranes were suspended in $300 \mathrm{mM}$ mannitol, $10 \mathrm{mM}$ Tris/16 mM Hepes, $\mathrm{pH} 7.5$, and $10 \mathrm{mM} \mathrm{MgSO}_{4}$ at a protein concentration of $5-10 \mathrm{mg} / \mathrm{ml}$. When BBMV were prepared from whole cortex of adult kidneys, three separate $\mathrm{Mg}^{2+}$ precipitation steps were used; with cortex from fetal kidneys, two steps were adequate to provide sufficient material of the same purity as adult BBMV. When ample fetal cortex was available, three $\mathrm{Mg}^{2+}$ aggregation steps were used: although the yield was reduced by the third $\mathbf{M g}^{2+}$ aggregation step, the purity of the preparation and data obtained under these conditions were not significantly different from those determined after two precipitation steps. In some studies, BBMV were prepared by the $\mathrm{Mg}^{2+}$ aggregation procedure from inner cortical, outer medullary tissue dissected from adult kidneys as described by Turner and Moran (10). Vesicles prepared from this isolated section of the kidney were used to validate studies in which kinetic parameters were assessed in BBMV prepared from the whole cortex.

\section{Enzyme determinations}

All enzyme assays were carried out at $37^{\circ} \mathrm{C}$ on both whole homogenate and isolated brush border fractions prepared from fetal and adult kidneys. Assays for alkaline phosphatase (11), gamma-glutamyltransferase (12), leucine aminopeptidase (13), maltase (10), and $\mathrm{Na}^{+} / \mathrm{K}^{+} \mathrm{ATP}$ ase (14) were performed as previously described. Protein was determined by the method of Lowry et al. (15) after an overnight digestion in $3 \mathrm{~N} \mathrm{NaOH}$.

\section{Transport studies}

Time course of glucose uptake. Uptake of $\mathrm{D}-\left[6-{ }^{3} \mathrm{H}(N)\right]$ glucose $(6.4$ $\mu \mathrm{Ci} / \mathrm{nmol}$; New England Nuclear, Boston, MA) was assayed at $20^{\circ} \mathrm{C}$ by a rapid filtration technique (Millipore Corp., Bedford, MA) using $0.65-\mu \mathrm{m}$ filters (6). Membrane vesicle suspensions (10 $\mu \mathrm{l}$ containing $5-10 \mathrm{mg}$ protein $/ \mathrm{ml}$ ) were preincubated for $1 \mathrm{~min}$ at $20^{\circ} \mathrm{C}$. Incubations were initiated by addition of $40 \mu \mathrm{l}$ of uptake medium; the concentrations of the components of these media are described in the figure and table legends. At specified times, uptakes were terminated by addition of $4 \mathrm{ml}$ of ice-cold $150 \mathrm{mM} \mathrm{NaCl}$ and $10 \mathrm{mM}$ Tris/16 mM Hepes, pH 7.5, with or without $0.5 \mathrm{mM}$ phlorizin (phlorizin did not increase the amount of vesicular associated glucose retained on the filters). Immediately thereafter, the vesicle suspensions were filtered and the incubation tubes and filters were washed with an additional 16 $\mathrm{ml}$ of ice-cold rinse solution. The filters were removed immediately from the filtration apparatus and dissolved in $10 \mathrm{ml}$ of scintillation fluid (ACS; Amersham Corp., Arlington Heights, IL). Radioactivity was meásured in a liquid scintillation counter (Tri-Carb 4430; Packard Instrument Co., Downers Grove, IL). Uptakes (expressed as picomoles per milligram protein) were calculated from the accumulated vesicular $D-\left[{ }^{3} \mathrm{H}\right]$ glucose, the specific activity of glucose in the medium, and the protein concentration of the vesicles. A correction for $\mathrm{D}-\left[{ }^{3} \mathrm{H}\right]$ glucose binding to the filters was made by subtracting activity retained on the filter at zero time.

Assessment of voltage clamp. Although the potassium ionophore, valinomycin, is commonly used to clamp the voltage in vesicles preequilibrated and incubated in potassium salts, it has recently been demonstrated that BBMV do not readily equilibrate when incubated with $\mathrm{KCl}(16)$. Fetal and adult BBMV have also been noted to exhibit different permeabilities for $\mathrm{K}^{+}(17)$. Since $\mathrm{K}^{+}$and valinomycin were therefore considered inadequate as a voltage clamp, an alternative technique was used: diffusion potentials were short-circuited with the protonophore, FCCP (carbonyl cyanide $p$-trifluoromethoxyphenylhydrazone). The efficacy of this method was tested by measuring the effect of FCCP on the 4-s uptake of glucose in the presence of either an inwardly directed $\mathrm{NaCl}$ or $\mathrm{Na}$ gluconate gradient. BBMV suspended in the buffered mannitol medium were incubated in a medium containing $100 \mathrm{mM}$ mannitol, $10 \mathrm{mM}$ Tris/16 mM Hepes (pH 7.5), $50 \mu \mathrm{M}$ D- $\left[{ }^{3} \mathrm{H}\right]$ glucose $(0.15 \mu \mathrm{Ci} / \mathrm{nmol}), \mathrm{FCCP}$ (or the vehicle for FCCP, ethanol), and either $100 \mathrm{mM} \mathrm{NaCl}$ or $100 \mathrm{mM} \mathrm{Na}$ gluconate for $4 \mathrm{~s}$ (timed with a metronome; preliminary experiments with $20 \mathrm{mM}$ glucose had shown that uptake was linear for $8 \mathrm{~s}$ ). The reaction was terminated by adding $4 \mathrm{ml}$ of ice-cold $150 \mathrm{mM} \mathrm{NaCl}, 10 \mathrm{mM}$ Tris/16 mM Hepes, (pH 7.5), and $0.5 \mathrm{mM}$ phlorizin. Thereafter, the vesicle suspensions were filtered, the tubes and filters were washed, and uptakes were measured as described above.

Kinetics of glucose transport. BBMV suspended in the buffered mannitol medium were added to a medium containing $100 \mathrm{mM}$ mannitol, $10 \mathrm{mM}$ Tris/16 mM Hepes, (pH 7.5), D- $\left[{ }^{3} \mathrm{H}\right]$ glucose $(50 \mu \mathrm{M}-1$ $\mathrm{mM} ; 0.15-0.4 \mu \mathrm{Ci} / \mathrm{nmol}$ ), and either $100 \mathrm{mM} \mathrm{NaCl}$ or $100 \mathrm{mM} \mathrm{KCl}$ $+1 \mathrm{mM}$ phlorizin. The reaction was initiated and terminated as described above. In some studies, the medium contained $100 \mu \mathrm{M}$ FCCP. Uptakés measured in the presence of $\mathrm{K}^{+}$and phlorizin were subtracted from those determined in the presence of $\mathrm{Na}^{+}$to obtain the $\mathrm{Na}^{+}$-dependent component of glucose uptake. The $V_{\max }$ and apparent $K_{\mathrm{m}}$ for glucose were determined from a Woolf-Augustinsson-Hofstee plot (18) of the initial rates at each glucose concentration.

\section{Phlorizin binding}

The equilibrium binding of phlorizin was determined in the following manner using the Millipore filtration technique: a 10- $\mu$ l aliquot of BBMV was preequilibrated at $37^{\circ} \mathrm{C}$ for $1 \mathrm{~min}$. At zero time, the reaction was initiated by addition of a $40-\mu \mathrm{l}$ aliquot of incubation medium (also at $37^{\circ} \mathrm{C}$ ) containing $100 \mathrm{mM}$ mannitol, $10 \mathrm{mM}$ Tris $/ 16 \mathrm{mM}$ Hepes (pH 7.5), $\left[{ }^{3} \mathrm{H}\right]$ phlorizin (50 nM-2 $\mu \mathrm{M} ; 5-33 \mu \mathrm{Ci} / \mathrm{nmol}[\mathrm{New}$ England Nuclear]), $100 \mu \mathrm{M}$ FCCP, and either $100 \mathrm{mM} \mathrm{NaCl}$ or 100 $\mathrm{mM} \mathrm{KCl}$. Since $\mathrm{Na}^{+}$-dependent phlorizin binding is sensitive to membrane potential (9), the voltage was clamped with the protonophore, FCCP. The reaction mixture was incubated at $37^{\circ} \mathrm{C}$ for $6 \mathrm{~min}$, a reaction time previously shown to guarantee complete equilibrium (19). Thereafter the reaction was terminated by addition of $4 \mathrm{ml}$ of ice-cold $150 \mathrm{mM} \mathrm{NaCl}, 10 \mathrm{mM}$ Tris/16 mM Hepes (pH 7.5), and 0.5 $\mathrm{mM}$ phlorizin. The vesicle suspension was filtered (Millipore filter; HAWP, $0.65 \mu \mathrm{m}$ ) and the tubes and filters washed with an additional $16 \mathrm{ml}$ of rinse solution. Specific $\mathrm{Na}^{+}$-dependent phlorizin binding was obtained by subtracting phlorizin binding measured in the presence of $\mathrm{K}^{+}$from that determined in the presence of $\mathrm{Na}^{+}$. From these corrected data the binding constants, $N_{0}$ (concentration of receptor sites), and $K_{d}$ (binding affinity), were determined by Scatchard analyses (20).

\section{Fluorescence polarization}

Steady state fluorescence polarization measurements were performed on a spectrofluorometer (SLM Instruments, Inc., Urbana, IL) modified to contain movable polarizers in the excitation and emission beams. A circulatory bath (Neslab Instruments, Inc., Portland, NH) was connected to the thermostated compartment and the temperature was monitored directly in the cuvette with a thermistor probe (Omega Engineering, Inc., Stamford, CT) connected to a digital ohmmeter. The fluorescent probe, 1,6-diphenyl-1,3,5-hexatriene (DPH), was dissolved in tetrahydrofuran at a concentration of $1.5 \mathrm{mM}$. The BBMV were suspended in $6 \mathrm{ml}$ of $154 \mathrm{mM} \mathrm{NaCl}$ in $100 \mathrm{mM}$ sodium phosphate buffer ( $\mathrm{pH} 7.4$ ), at a concentration of $20-30 \mu \mathrm{g} / \mathrm{ml}$. At these low protein concentrations, light scattering was minimal. The BBMV suspension was divided into two equal aliquots. To one aliquot, $1 \mu \mathrm{l}$ of the stock DPH solution was added $([\mathrm{DPH}]=0.5 \mu \mathrm{M})$; the other aliquot served as the sample blank. Both aliquots were incubated at $37^{\circ} \mathrm{C}$ for $20 \mathrm{~min}$. The DPH was excited at $357 \mathrm{~nm}$ and emission was measured 
at $430 \mathrm{~nm}$. Steady state fluorescence polarization was expressed in terms of anisotropy $(r)$ computed according to the relationship: $r=\left(I_{11}\right.$ $\left.-I_{\perp}\right) /\left(I_{11}+2 I_{\perp}\right)$ where $I_{11}$ is fluorescence intensity with emission and excitation polarizers parallel; and $I_{\perp}$ is fluorescence intensity with the polarizers perpendicular. The data were corrected for unequal transmission of differently polarized light and for intrinsic fluorescence. The latter correction was made by subtracting the fluorescence of the sample blank from the fluorescence of the sample containing DPH.

\section{Analysis of data}

All experiments were performed on at least three fresh membrane vesicle preparations. In each experiment, uptakes were determined on triplicate or quadruplicate aliquots of BBMV. All data are expressed as the mean \pm SE. To determine statistical significance, the data were evaluated using the $t$ test. Regression lines were calculated by the method of least squares.

\section{Results}

Enzymatic characterization of vesicle preparation. The specific activities and enrichment of four brush border marker enzymes (leucine aminopeptidase, alkaline phosphatase, maltase, and gamma-glutamyltransferase) and one basolateral marker enzyme $\left(\mathrm{Na}^{+} / \mathrm{K}^{+}\right.$ATPase) are provided in Table I. The specific activities of all five enzymes were significantly higher in the homogenates from the adult kidney as compared with homogenates from the fetal kidney. Note, however, that each of the enzymes exhibited a different developmental profile. The specific activity of leucine aminopeptidase was only slightly (1.3 times) greater in the adult than in the fetal homogenate. Indeed, in 3 of 10 preparations, the specific activity of leucine aminopeptidase was equal in the fetal and adult ho- mogenates. In contrast, the specific activities of alkaline phosphatase, maltase, gamma-glutamyltransferase, and $\mathrm{Na}^{+} / \mathrm{K}^{+}$ ATPase were 2.5-, 4-, 5.5-, and 2-fold greater, respectively, in the adult compared with the fetal homogenate. Despite these differences in homogenate specific activities, each of the brush border marker enzymes was enriched 8-11-fold in both the fetal and adult BBMV preparations. Since $\mathrm{Na}^{+} / \mathrm{K}^{+}$ATPase activity was not detectable in either BBMV preparation, neither preparation appeared to be significantly contaminated with basolateral membranes.

Osmotic reactivity studies. To determine whether glucose uptake into fetal BBMV represents transport and/or substrate binding, experiments were performed to examine the effect of intravesicular volume on equilibrium uptake of glucose. As depicted in Fig. 1, glucose uptake was inversely related to medium osmolarity in vesicles prepared from both fetal and adult kidneys. The fetal and adult BBMV thus were osmotically reactive. Further, neither type of vesicle bound glucose, as evidenced by the extrapolation of uptake to zero at infinite medium osmolarity. From the known concentration of glucose in the medium, an estimation of intravesicular volume was made by assuming an equilibrium distribution of glucose at $60 \mathrm{~min}$. At $300 \mathrm{mosM}$, the intravesicular volume of the BBMV from the adult was $1.2 \pm 0.1 \mu \mathrm{l} / \mathrm{mg}$ protein; that of the fetal preparation was $0.75 \pm 0.04 \mu \mathrm{l} / \mathrm{mg}$ protein $(P<0.01)$.

Time course of $\mathrm{Na}^{+}$-dependent glucose uptake. The time course of glucose uptake into adult and fetal brush border membrane vesicles is illustrated in Fig. 2 . In both preparations, an initial $100-\mathrm{mM} \mathrm{NaCl}$ gradient between medium and vesicle (medium $>$ vesicle) induced a rapid uptake of glucose that reached a maximum in $1 \mathrm{~min}$. Thereafter, there was a net

Table I. Enzyme Activities in Whole Homogenates and BBMV from Fetal and Adult Rabbit Kidneys

\begin{tabular}{|c|c|c|c|c|}
\hline Enzyme & Fetal & Adult & $\mathrm{A} / \mathrm{F}$ & $P$ \\
\hline \multicolumn{5}{|l|}{ Leucine aminopeptidase } \\
\hline Homogenate $(\mathrm{H})$ & $184 \pm 6(10)$ & $240 \pm 8(10)$ & 1.3 & $<0.01$ \\
\hline Brush border (BB) & $1,823 \pm 171$ & $2,415 \pm 202$ & 1.3 & $<0.05$ \\
\hline Enrichment (BB/H) & $10.4 \pm 1.1$ & $10.2 \pm 0.9$ & & NS \\
\hline \multicolumn{5}{|l|}{ Alkaline phosphatase } \\
\hline Homogenate $(\mathrm{H})$ & $92.3 \pm 7.9(10)$ & $226 \pm 20(10)$ & 2.4 & $<0.001$ \\
\hline Brush border (BB) & $895 \pm 62$ & $1,811 \pm 210$ & 2.0 & $<0.001$ \\
\hline Enrichment (BB/H) & $10.2 \pm 0.9$ & $8.0 \pm 0.5$ & & $<0.05$ \\
\hline \multicolumn{5}{|l|}{ Maltase } \\
\hline Homogenate (H) & $19.0 \pm 2.7(9)$ & $77.3 \pm 5.2(10)$ & 4.1 & $<0.001$ \\
\hline Brush border (BB) & $150 \pm 29$ & $831 \pm 83$ & 5.5 & $<0.001$ \\
\hline Enrichment (BB/H) & $8.7 \pm 0.9$ & $10.5 \pm 0.7$ & & NS \\
\hline \multicolumn{5}{|c|}{ Gamma-glutamyltransferase } \\
\hline Homogenate (H) & $137 \pm 16(10)$ & $753 \pm 84(10)$ & 5.5 & $<0.001$ \\
\hline Brush border (BB) & $1,326 \pm 193$ & $7,144 \pm 1,092$ & 5.4 & $<0.001$ \\
\hline Enrichment (BB/H) & $9.9 \pm 1.0$ & $9.4 \pm 0.8$ & & NS \\
\hline \multicolumn{5}{|l|}{$\mathrm{Na}^{+} / \mathrm{K}^{+}$ATPase } \\
\hline Homogenate (H) & $7.08 \pm 1.09(6)$ & $15.3 \pm 1.7(7)$ & 2.2 & $<0.01$ \\
\hline Brush border (BB) & ND & ND & & \\
\hline Enrichment (BB/H) & - & - & & \\
\hline
\end{tabular}

All enzyme activities are expressed as the mean $\mathrm{nmol} / \mathrm{min}$ per $\mathrm{mg}$ protein $\pm \mathrm{SE}$. The numbers in parentheses indicate the numbers of membrane preparations studied. A/F, ratio of specific activity in the adult to specific activity in the fetus. ND, not detectable. $P$ indicates statistical significance between fetal and adult preparations as determined by $t$ test. 


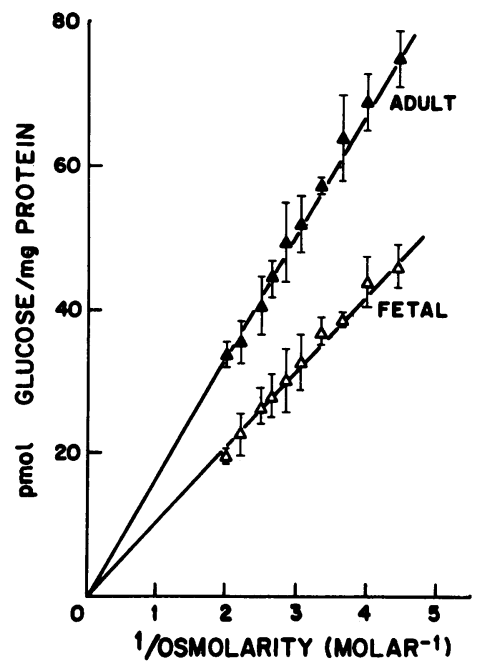

Figure 1. Effect of medium osmolarity on glucose uptake. Vesicles were prepared in $300 \mathrm{mM}$ mannitol, $10 \mathrm{mM}$ Tris/ $16 \mathrm{mM}$ Hepes (pH 7.5), and 10 $\mathrm{mM} \mathrm{MgSO}_{4}$. Uptake was measured after $60 \mathrm{~min}$ in a medium containing $50 \mu \mathrm{M}$ $D-\left[{ }^{3} \mathrm{H}\right]$ glucose, $10 \mathrm{mM}$ Tris/ $16 \mathrm{mM}$ Hepes (pH 7.5), and mannitol to the indicated osmolarity. The data represent the mean $\pm \mathrm{SE}$ of three experiments in the adult $(\Lambda)$ and three experiments in the fetus $(\Delta)$. efflux of glucose. This demonstration of a transient overshoot of the intravesicular glucose concentration above its equilibrium value indicates that fetal and adult brush border preparations are capable of catalyzing concentrative uptake of glucose in the presence of an inwardly directed $\mathrm{Na}^{+}$gradient. The characteristics of glucose transport in the two vesicle preparations thus are qualitatively quite similar. However, there appear to be quantitative differences in the glucose transport system in fetal and adult BBMV: $(a)$ at each time point, the uptake of glucose was less in the fetal preparation compared with the adult and $(b)$ the magnitude of the overshoot relative to the equilibrium uptake, i.e., extent of concentrative uptake, was significantly lower in the fetal BBMV $(4.9 \pm 0.3)$ than in the adult preparation $(9.1 \pm 1.1), P<0.05$.

Effect of sugar analogues on $\mathrm{Na}^{+}$-dependent glucose transport. The inhibitory effect of several compounds on the initial rates of glucose uptake into fetal and adult vesicle preparations is detailed in Table II. In both preparations, the $\mathrm{Na}^{+}$-dependent uptake of $50 \mu \mathrm{M}$ D- $\left[{ }^{3} \mathrm{H}\right]$ glucose at $10 \mathrm{~s}$ was highly sensitive to inhibition by cold D-glucose at a concentration of 1 mM. L-Glucose did not inhibit initial uptake rates in the adult preparation, indicating the specificity of the transport system. A slight, but significant inhibition (10\%) by L-glucose was ob-

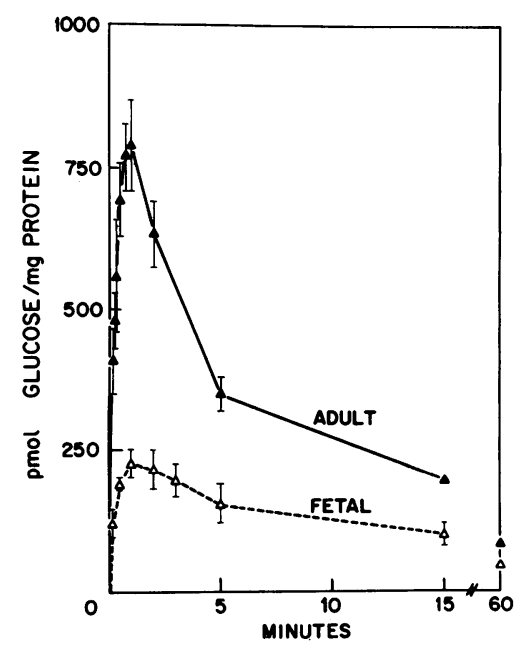

Figure 2. Time course of glucose uptake into BBMV. Vesicles were prepared in $300 \mathrm{mM}$ mannitol, $10 \mathrm{mM}$ Tris/ $16 \mathrm{mM}$ Hepes (pH 7.5), and $10 \mathrm{mM}$ $\mathrm{MgSO}_{4}$. Uptake of 50 $\mu \mathrm{M}$ D- $\left[{ }^{3} \mathrm{H}\right] \mathrm{glucose}$ was determined in a medium containing 100 $\mathrm{mM} \mathrm{NaCl}, 100 \mathrm{mM}$ mannitol, and $10 \mathrm{mM}$ Tris/ $16 \mathrm{mM}$ Hepes (pH 7.5). The data represent the mean $\pm S E$ of nine experiments in the adult $(\Delta)$ and five in the fetus $(\Delta)$.
Table II. Effect of Sugar Analogues on $\mathrm{Na}^{+}$-dependent Uptake of D-Glucose by Brush Border Membranes from Fetal and Adult Kidneys

\begin{tabular}{lccc}
\hline & \multicolumn{3}{c}{ Relative rate of D-glucose } \\
uptake & \\
\cline { 2 - 3 } \multicolumn{1}{c}{ Analogue } & Fetal (3) & Adult (3) & $P$ \\
\hline & \multicolumn{3}{c}{$\%$} \\
Control $\left(50 \mu M\left[{ }^{3} \mathrm{H}\right]\right.$ glucose $)$ & 100 & 100 & \\
L-Glucose $(1 \mathrm{mM})$ & $88.9 \pm 3.3$ & $101.4 \pm 2.3$ & $<0.025$ \\
D-Glucose $(1 \mathrm{mM})$ & $15.0 \pm 0.7$ & $18.7 \pm 1.4$ & NS \\
& & & \\
\hline
\end{tabular}

Data represent the mean $\pm \mathrm{SE}$. The numbers in parentheses indicate the numbers of paired membrane preparations studied in the presence and absence of each of the analogues. $P$ indicates statistical significance between fetal and adult preparations as determined by $t$ test.

served in the fetal brush border preparation, suggesting that the fetal glucose transporter has a slightly lower substrate specificity.

Specificity of $\mathrm{Na}^{+}$stimulation of glucose transport. The specificity of $\mathrm{Na}^{+}$in enhancing the rate of D-glucose uptake in renal BBMV is shown in Fig. 3. With adult BBMV, glucose uptake was rapid in the presence of an inwardly directed $\mathrm{Na}^{+}$ gradient, rising to levels several times that seen at equilibrium, in this case eightfold. This overshoot was abolished when $\mathrm{NaCl}$ was replaced by either $\mathrm{KCl}$ or $\mathrm{LiCl}$. A similar profile was seen with fetal vesicles: a $\mathrm{Na}^{+}$gradient (medium > vesicle) drove glucose transport approximately fourfold above the equilibrium value, whereas neither $\mathrm{K}^{+}$nor $\mathrm{Li}^{+}$stimulated uptake. These results demonstrate that the fetal glucose transport system has the same specificity for $\mathrm{Na}^{+}$as the adult transporter.

Effect of phlorizin on $\mathrm{Na}^{+}$-dependent glucose transport. Phlorizin is a specific inhibitor of $\mathrm{Na}^{+}$-dependent glucose transport in renal BBMV (9). In the adult preparation (Fig. 4), phlorizin inhibited the overshoot phenomenon and, in the presence of phlorizin, $\mathrm{Na}^{+}$-dependent glucose transport was reduced almost to the levels of transport found in the absence of sodium, i.e., in a mannitol medium. An identical transport profile was observed in the fetal BBMV (Fig. 4): the fourfold overshoot above equilibrium induced by a $100-\mathrm{mM} \mathrm{Na}^{+}$gradient was eliminated by phlorizin and glucose uptake was reduced to the level of transport found in the absence of $\mathrm{Na}^{+}$.

Energetics of $\mathrm{Na}^{+}$-dependent glucose transport. The adult $\mathrm{Na}^{+}$-dependent glucose transport process is electrogenic, i.e., the translocation of the sugar is coupled to the net movement of positive charge $(7,21)$. Therefore, transport is influenced by the electrochemical potential across the membrane (22). Anions that penetrate the brush border membrane and generate an inside negative electrical potential (PD) permit uphill $\mathrm{Na}^{+}$-dependent transport of glucose. Because $\mathrm{NO}_{3}^{-}$is more permeable than $\mathrm{Cl}^{-}$, it facilitates the more rapid development of the membrane potential and enhances uptake and accumulation of glucose relative to that seen with $\mathrm{Cl}^{-}$. As demonstrated in Fig. 5, the $\mathrm{NO}_{3}^{-}$anion, when compared with $\mathrm{Cl}^{-}$, stimulated glucose uptake and enhanced the overshoot in the fetal and adult BBMV. Furthermore, the magnitude of stimulation was comparable $(\sim 40 \%)$ in the fetal and adult preparations. This finding suggests that the $\mathrm{Na}^{+}$-dependent glucose transport system in the fetus is influenced by the membrane 

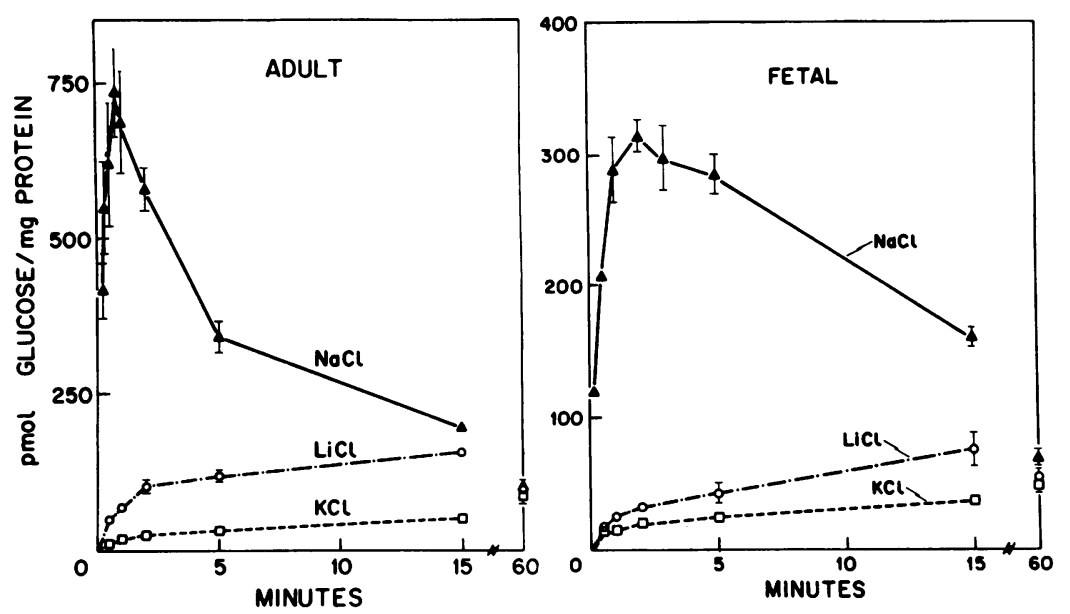

Figure 3. Cation specificity of glucose uptake. Vesicles were prepared in $300 \mathrm{mM}$ mannitol, $10 \mathrm{mM}$ Tris/ $16 \mathrm{mM}$ Hepes (pH 7.5), and $10 \mathrm{mM} \mathrm{MgSO}_{4}$. Uptake of $50 \mu \mathrm{M} \mathrm{D}-\left[{ }^{3} \mathrm{H}\right]$ glucose was determined in a medium containing $100 \mathrm{mM}$ mannitol, $10 \mathrm{mM}$ Tris/ $16 \mathrm{mM}$ Hepes (pH 7.5), and either $100 \mathrm{mM}$ $\mathrm{NaCl}, \mathrm{LiCl}$, or $\mathrm{KCl}$. The data represent the mean $\pm \mathrm{SE}$ of three experiments in the adult and three in the fetus.

potential and thus involves the net transfer of a positive charge, i.e., is electrogenic.

Kinetics of $\mathrm{Na}^{+}$-dependent glucose transport. It has recently been shown that there are two sodium-coupled D-glucose carriers in adult renal BBMV (13): a low affinity, high capacity system with a 1:1 sodium/glucose stoichiometry identified in BBMV from the outer cortex, and a high affinity, low capacity system with a 2:1 sodium/glucose stoichiometry identified in BBMV prepared from the inner cortex and outer medulla. Note that the developing kidney exhibits a centrifugal pattern of nephron growth, which in some species is not completed until the postnatal period (23). In fact, in the rabbit, nephrogenesis continues until $\sim 3$ wk postpartum (24). Furthermore, whereas juxtamedullary proximal convoluted tubules are formed 10-15 d before birth, superficial tubules are not developed at birth. Only the kinetic parameters of the high affinity, low capacity carrier thus were determined in both the fetal and adult BBMV, since this carrier is located in the region of the kidney most highly developed before birth. Note that although BBMV were obtained from the whole cortex of fetal and adult kidneys, it was possible to examine selectively the high affinity carrier by restricting the range of glucose concentrations used in the kinetic studies. In six experiments in which adult BBMV were prepared from inner cortical/outer medullary tissue the kinetic parameters were identical to those determined with adult BBMV prepared from whole cortex $\left(K_{\mathrm{m}}=0.13 \pm 0.02\right.$ $\mathrm{mM}$ and $V_{\max }=11.1 \pm 1.5 \mathrm{nmol} / \mathrm{min}$ per $\mathrm{mg}$ for BBMV of inner cortex/outer medulla vs. $K_{\mathrm{m}}=0.15 \pm 0.02$ and $V_{\max }$ $=11.9 \pm 1.2 \mathrm{nmol} / \mathrm{min}$ per $\mathrm{mg}$ for BBMV of whole cortex). These data indicate that this approach permits a valid assessment of the kinetics of the inner cortical/outer medullary, high affinity transporter even though vesicles were prepared from whole cortex.

When kinetic experiments were performed in the absence of a voltage clamp, the $K_{\mathrm{m}}$ for glucose $(0.15 \mathrm{mM})$ was similar in both the fetal and adult BBMV, but $V_{\max }$ was sixfold higher in the adult BBMV (Fig. $6 \mathrm{~A}$ ). However, glucose transport is electrogenic and, therefore, the $V_{\max }$ of this transporter is sensitive to the transmembrane potential. To assess the possibility that the disparity in $V_{\max }$ in fetal and adult vesicles was solely consequent to differences in the prevailing PD across these membranes, kinetic studies were also performed under conditions in which the PD was dissipated in fetal and adult vesicles. To ensure that the PD could be adequately short circuited, initial rates of glucose transport were measured in adult BBMV in the presence and absence of the protonophore FCCP. As shown in Table III, in the absence of FCCP, the initial rate of glucose uptake was significantly greater when the
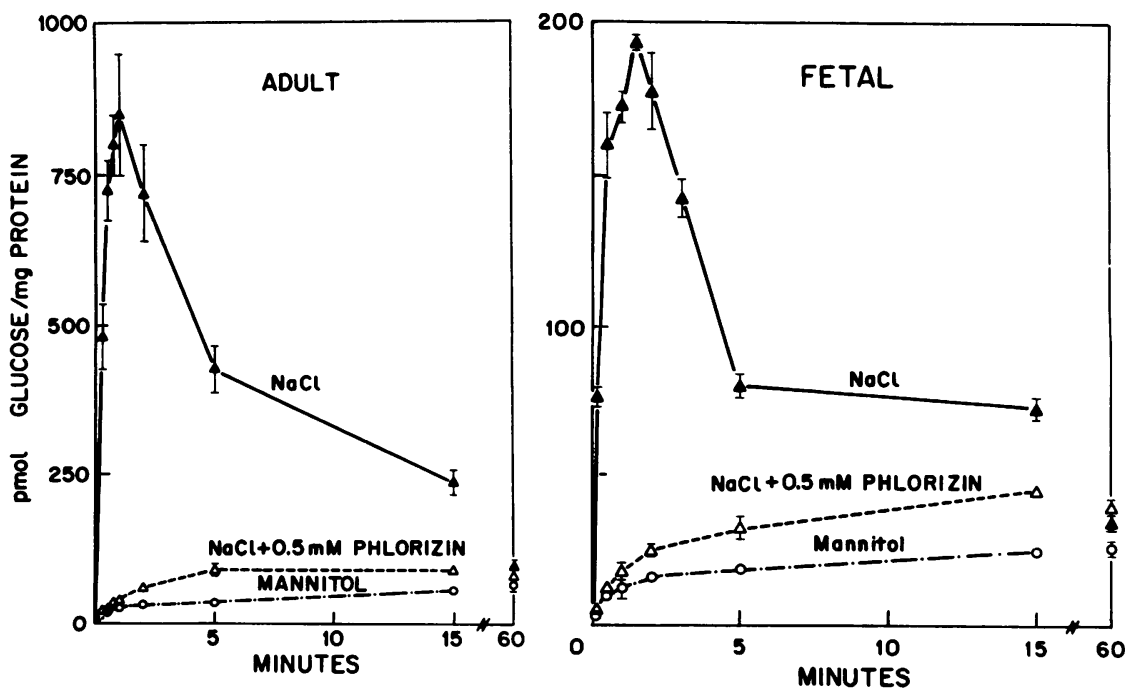

Figure 4. Phlorizin sensitivity of glucose uptake. Vesicles were prepared in $300 \mathrm{mM}$ mannitol, $10 \mathrm{mM}$ Tris/16 mM Hepes ( $\mathrm{pH} 7.5$ ), and $10 \mathrm{mM} \mathrm{MgSO}_{4}$. Uptake of $50 \mu \mathrm{M}$ D- $\left[{ }^{3} \mathrm{H}\right]-$ glucose was determined in a medium containing $100 \mathrm{mM} \mathrm{NaCl}, 100 \mathrm{mM}$ mannitol, 10 $\mathrm{mM}$ Tris/ $16 \mathrm{mM}$ Hepes (pH 7.5), $\pm 0.5 \mathrm{mM}$ phlorizin. The data represent the mean $\pm S E$ of four experiments in the adult and three in the fetus. 

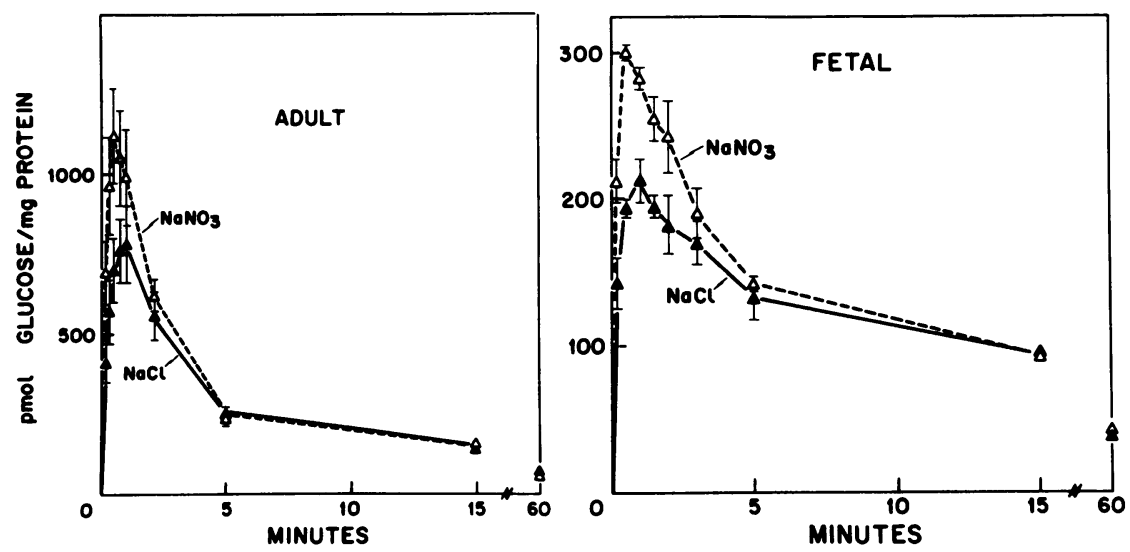

Figure 5. Effect of anions on the $\mathrm{Na}^{+}$-dependent uptake of glucose. Vesicles were prepared in $300 \mathrm{mM}$ mannitol, $10 \mathrm{mM}$ Tris $/ 16 \mathrm{mM}$ Hepes (pH 7.5), and $10 \mathrm{mM} \mathrm{MgSO}_{4}$. Uptake of $50 \mu \mathrm{M}$ D- $\left[{ }^{3} \mathrm{H}\right]$ glucose was determined in a medium containing $100 \mathrm{mM}$ mannitol, 10 $\mathrm{mM}$ Tris/16 mM Hepes (pH 7.5), and either $100 \mathrm{mM} \mathrm{NaCl}$ or $\mathrm{NaNO}_{3}$. The data represent the mean $\pm \mathrm{SE}$ of four experiments in the adult and three in the fetus.

more permeant anion $\mathrm{Cl}^{-}$replaced the virtually impermeant anion gluconate. In the presence of FCCP, glucose uptake was stimulated in the presence of gluconate and inhibited in the presence of chloride so that differences in uptake in the presence of chloride and gluconate were markedly reduced. These findings indicate that the inhibitory effect of an $\mathrm{Na}^{+}$diffusion potential (in the case of $\mathrm{Na}$ gluconate) and the stimulating effect of a $\mathrm{Cl}^{-}$diffusion potential (in the case of $\mathrm{NaCl}$ ) can both be virtually eliminated by providing a path for protons to short circuit the respective potentials. Insofar as these findings indicate that this protonophore can effectively dissipate diffusion potentials, the kinetics of glucose transport were reexamined in the presence of $100 \mu \mathrm{M} \mathrm{FCCP.}$

In the presence of FCCP, the $K_{\mathrm{m}}$ for glucose $(\sim 0.3 \mathrm{mM})$ was again similar in both preparations; however, the $V_{\max }$ in the adult was only twice that in the fetus (Fig. $6 \mathrm{~B}$ ). Note that the diminished disparity in $V_{\max }$ was the result of two phenomena: in the presence of the voltage clamp, $V_{\max }$ increased significantly in fetal BBMV ( 2.0 vs. $4.4 \mathrm{nmol} / \mathrm{min}$ per $\mathrm{mg}$ ), but decreased in adult vesicles (11.9 vs. $9.7 \mathrm{nmol} / \mathrm{min}$ per $\mathrm{mg}$ ). This finding strongly suggests that the marked difference in $V_{\max }$ in unperturbed fetal and adult vesicles was, in part, con- sequent to differences in PD in fetal and adult BBMV. This finding also suggests that the voltage clamp abolished a $\mathrm{Na}^{+}$ diffusion potential in the fetal vesicles while it abolished a chloride diffusion potential in the adult preparation. The response to the protonophore thus implies that the relative conductances (G) of $\mathrm{Na}^{+}$and $\mathrm{Cl}^{-}$differ in fetal and adult membranes: $G_{N a}$ must exceed $G_{C}$ in the fetus, but be less than $G_{C I}$ in the adult. Finally, since $V_{\max }$ remained significantly higher in the adult BBMV, despite the presence of the voltage clamp, these studies also suggest that the number of glucose carriers and/or turnover number of the carriers must be greater in the adult than fetal membranes.

Phlorizin binding. Since phlorizin binding has been widely used to estimate the number of glucose carriers in renal BBMV (19), the hypothesis that the increase in $V_{\max }$ from fetus to adult results from an increase in the number of glucose transporters was tested directly by measuring the number of $\mathrm{Na}^{+}-$ dependent phlorizin binding sites in each preparation. A Scatchard analysis of the binding data (Fig. 7) showed that the $K_{d}$ for phlorizin was not significantly different in the adult and fetal BBMV $(0.54 \pm 0.08 \mu \mathrm{M}$ [adult] vs. $0.38 \pm 0.07 \mu \mathrm{M}$ [fetal]). However, the number of binding sites in the adult was 3.5

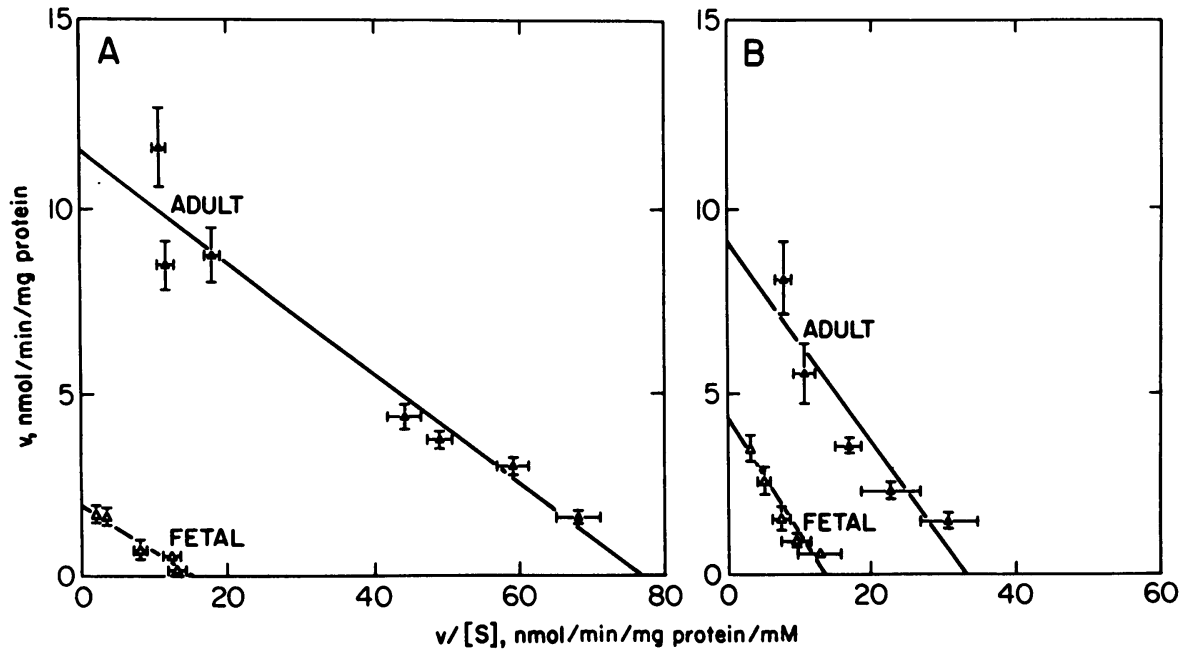

Figure 6. Woolf-Augustinsson-Hofstee plots of the initial rates of $\mathrm{Na}^{+}$-dependent glucose uptake in the presence and absence of FCCP in fetal $(\Delta)$ and adult $(\Delta)$ BBMV. Vesicles were prepared in $300 \mathrm{mM}$ mannitol, $10 \mathrm{mM}$ Tris/ $16 \mathrm{mM}$ Hepes (pH 7.5), and $10 \mathrm{mM} \mathrm{MgSO}_{4}$. The incubation medium contained $100 \mathrm{mM}$ mannitol, 10 $\mathrm{mM}$ Tris/16 mM Hepes (pH 7.5), and D$\left[{ }^{3} \mathrm{H}\right]$ glucose $(50 \mu \mathrm{M}-1 \mathrm{mM})$ and either 100 $\mathrm{mM} \mathrm{NaCl}$ or $100 \mathrm{mM} \mathrm{KCl}+1.0 \mathrm{mM}$ phlorizin. The $\mathrm{Na}^{+}$-dependent component of glucose transport was determined from the differences in uptake in the presence of $\mathrm{Na}^{+}$and that measured in the presence of $\mathrm{K}^{+}$and phlorizin. (A) Uptake was determined after $2 \mathrm{~s}$ in the absence of FCCP. A least squares analysis of the corrected data yielded the following kinetic parameters:

$K_{\mathrm{m}}=0.12 \pm 0.02 \mathrm{mM} ; V_{\max }=2.0 \pm 0.2 \mathrm{nmol} / \mathrm{min}$ per $\mathrm{mg}, r=0.984$ for fetal BBMV and $K_{\mathrm{m}}=0.15 \pm 0.02 \mathrm{mM} ; V_{\max }=11.9 \pm 1.2, r=0.988$ for adult BBMV. The data represent the mean \pm SE for three experiments in both preparations. $(B)$ Uptake was determined after $4 \mathrm{~s}$ in the presence of FCCP. A least squares analysis of the data yielded the following kinetic parameters: $K_{\mathrm{m}}=0.36 \pm 0.07 \mathrm{mM} ; V_{\max }=4.4 \pm 0.4 \mathrm{nmol} / \mathrm{min}$ per mg, $r=0.964$ for fetal BBMV and $K_{\mathrm{m}}=0.32 \pm 0.07 \mathrm{mM} ; V_{\max }=9.7 \pm 1.4 \mathrm{nmol} / \mathrm{min}$ per $\mathrm{mg}, r=0.938$ for adult BBMV. The data represent the mean $\pm \mathrm{SE}$ for five experiments in the adult and four in the fetus. 
Table III. Effect of FCCP on Glucose Transport in Adult BBMV

\begin{tabular}{rcc}
\hline [FCCP] & $\mathrm{NaCl}$ & Na gluconate \\
\hline$\mu M$ & & \\
0 & $3.65 \pm 0.08$ & $1.46 \pm 0.06^{*}$ \\
20 & $3.40 \pm 0.11$ & $2.58 \pm 0.06^{\ddagger}$ \\
100 & $3.12 \pm 0.11^{\S}$ & $2.48 \pm 0.12^{\ddagger}$ \\
\hline
\end{tabular}

Glucose uptake is expressed as the mean $\mathrm{nmol} / \mathrm{min}$ per $\mathrm{mg}$ protein \pm SE.

$* P<0.001$ for uptake in $\mathrm{NaCl}$ vs. $\mathrm{Na}$ gluconate.

${ }^{\ddagger} P<0.001$ for uptake in the presence of 20 or $100 \mu \mathrm{M}$ FCCP compared with the absence of FCCP in a Na gluconate medium.

${ }^{\S} P<0.005$ for uptake in the presence of $100 \mu \mathrm{M}$ FCCP compared with the absence of FCCP in a $\mathrm{NaCl}$ medium.

times that in the fetus $(79.7 \pm 5.5$ vs. $22.5 \pm 2.6 \mathrm{pmol} / \mathrm{mg}$ protein).

Membrane fluidity. To assess changes in membrane fluidity during development, the fluidity of the membranes was measured by determining the steady state fluorescence polarization of the fluorescent probe, DPH. As shown in Table IV, the anisotropy of DPH was significantly lower (the fluidity was higher) in the fetal than in the adult membranes at both $20^{\circ} \mathrm{C}$, the temperature at which transport was measured, and $37^{\circ} \mathrm{C}$, the temperature at which enzyme activities were determined. In both the fetal and adult membranes, fluidity was significantly higher at $37^{\circ} \mathrm{C}$ than $20^{\circ} \mathrm{C}$.

\section{Discussion}

The present studies provide the first direct evidence to indicate that the $\mathrm{Na}^{+}$-dependent glucose transport system is developed in the renal proximal tubule brush border membranes of the fetal rabbit late in gestation. This fetal transport system is qualitatively similar to that of the adult: it is stereospecific, electrogenic, cation specific, and phlorizin sensitive (Table II, Figs. 2-5). There are, however, two significant quantitative differences: $(a)$ the concentrating ability of the vesicles (measured by the height of the overshoot relative to the equilibrium value) is reduced in the fetal preparation compared with the adult (Figs. $2-5)$ and $(b)$ the $V_{\max }$ in the fetal preparation is significantly less than that determined for the adult (Fig. 6).

Analysis of the brush border marker enzymes (Table I) strongly suggests that the differences in glucose transport de-

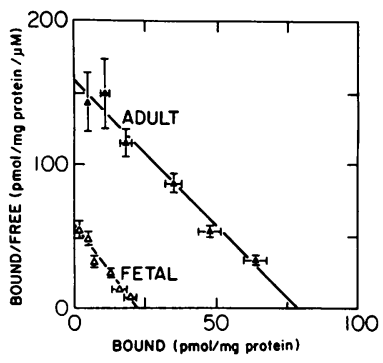

Figure 7. A Scatchard analysis of sodium-dependent phlorizin binding to fetal $(\Delta)$ and adult $(\Delta)$ BBMV. Equilibrium binding of phlorizin was determined as described in Methods. A least squares analysis of the data yielded the following parameters: $K_{\mathrm{d}}=0.41 \pm 0.08 \mu \mathrm{M}, N_{0}$ $=22.5 \pm 2.6 \mathrm{pmol} / \mathrm{mg}$ protein, $r$ $=0.963$ for fetal BBMV and $K_{d}$

$=0.57 \pm 0.09 \mu \mathrm{M}, N_{0}=70.7 \pm 5.5 \mathrm{pmol} / \mathrm{mg}$ protein, $r=0.985$ for adult $B B M V$. The data represent the mean $\pm S E$ for five experiments in the adult and four in the fetus. scribed above in fetal and adult BBMV reflect developmental changes and not simply differences in the degree of purification of the vesicle preparations. The rather minor, albeit significant, difference in activity of the brush border enzyme, leucine aminopeptidase, in the fetal and adult homogenates implies that this enzyme is virtually fully developed in the fetal kidney. Insofar as leucine aminopeptidase is membrane bound, the similarity in homogenate enzyme activity further implies that the relative amount of brush border membrane is similar in fetal and adult cortices. The virtually identical enrichment of this enzyme in the two BBMV preparations thus provides strong evidence that the fetal and adult membranes are purified to a very similar extent. This conclusion is supported by the observation that the other brush border marker enzymes were also comparably enriched in the fetal and adult BBMV. Interestingly, in contrast to leucine aminopeptidase, the specific activities of the other brush border marker enzymes were significantly different in fetal and adult homogenates. As the ratio of adult to fetal enzyme activities in the homogenates differed for each of the enzymes assayed, these disparities suggest that each of these enzymes is expressed at a different stage of development. Others $(13,25)$ have reported similar developmental profiles for rat kidney, i.e., leucine aminopeptidase appears to be fully developed at birth, whereas alkaline phosphatase and maltase increase some three- and eightfold, respectively, in the neonatal period.

Since substrate uptake may represent the sum of transport into the vesicles plus nonspecific binding, an additional criterion for a quantitative comparison of transport at various stages of development is that the relative contributions of transport and binding do not vary at each developmental stage. The present study demonstrates that virtually all glucose uptake represents transport at each stage of development (Fig. 1). Note, however, that this finding contrasts with the significant substrate binding detected in BBMV prepared from newborn rats (26). In the latter studies, whole kidneys were homogenized and divalent cations were omitted (26). In the present study, only the cortex was homogenized, and the isolation procedure included repeated $\mathrm{Mg}^{2+}$ aggregation steps. These modifications in the preparative technique may have been important in obtaining a highly purified brush border fraction from the rabbit fetal kidney in which glucose did not bind nonspecifically.

Based on the above considerations, the differences in glucose transport in the fetal and adult brush border vesicles (Figs. 2-6) apparently reflect developmental changes in transport as the fetal kidney matures. In contrast to the adult, the cortex of

Table IV. Fluorescence Anisotropy of DPH in Brush Border Membranes

\begin{tabular}{cccc}
\hline Temperature & Fetal membranes (5) & Adult membranes (8) & $P$ \\
\hline $20^{\circ} \mathrm{C}$ & $0.256 \pm 0.006$ & $0.276 \pm 0.003$ & $<0.01$ \\
$37^{\circ} \mathrm{C}$ & $0.215 \pm 0.004$ & $0.237 \pm 0.004$ & $<0.005$
\end{tabular}

Data represent the mean $\pm \mathrm{SE}$. The numbers in parentheses indicate the number of membrane preparations studied at the temperatures indicated. $P$ indicates statistical significance between fetal and adult preparations as determined by $t$ test. 
the fetal and neonatal kidney has nephrons at various stages of differentiation and development. Immature tubules are located in the outer cortical region (the nephrogenic zone), while the most mature nephrons are located in the innermost section of the cortex. Because the glucose transporter is kinetically different in the outer and inner cortex (10), the kinetic parameters were examined under conditions that would allow comparison between the transporter in the more mature, inner cortical nephrons of the fetus and those in the same cortical region in the adult. The apparent affinity of this inner cortical, high affinity, low capacity transport system for glucose was indistinguishable in the fetal and adult vesicles, whereas the $V_{\max }$ was significantly lower in the fetus. Insofar as these studies compared the kinetic behavior of the glucose carrier in similar anatomical sites in the fetal and adult kidneys, these findings suggest that the maturational changes in glucose transport are consequent to factors other than the maturational diversity of the fetal proximal tubules.

Several mechanisms may be responsible for the maturational changes in glucose transport. The magnitude of the glucose overshoot is critically dependent on the permeability of the anion relative to sodium (7): the lower the anion permeability relative to sodium, the smaller the inside negative PD that will be generated. Since $\mathrm{Na}^{+}$-dependent glucose transport is electrogenic, a reduction in the transmembrane potential would limit the accumulation of glucose. The present studies, as well as preliminary studies in which ionic permeabilities were assessed with a fluorescent probe (17), suggest that the conductance of $\mathrm{Cl}^{-}$, relative to that of $\mathrm{Na}^{+}$, is significantly lower in BBMV from neonatal animals compared with those of the adult. While there may not be a precise parallelism between in vitro and in vivo ionic conductances (16), maturational changes in relative $\mathrm{Cl}^{-}$and $\mathrm{Na}^{+}$conductances could account for the increment in the magnitude of the glucose overshoot with development (Figs. 2-6). A diminished capacity to concentrate glucose could also be consequent to a more rapid dissipation of the $\mathrm{Na}^{+}$gradient in $\mathrm{BBMV}$ from immature animals. Such a mechanism has been implicated in other developmental studies in which reduced $\mathrm{Na}^{+}$-dependent solute entry has been observed in renal $(28,29)$ and intestinal $(30)$ BBMV. Finally, in computer-simulated analyses, Heinz and Weinstein (27) have demonstrated that the height of the overshoot varies directly with the maximal rate of the carrier.

To address the mechanism for the maturational increase in the $V_{\max }$ for glucose transport, the dependence of $V_{\max }$ on the transmembrane potential was assessed, the number of transporters in each preparation was quantitated using $\left[{ }^{3} \mathrm{H}\right]-$ phlorizin binding techniques, and the turnover number ( $V_{\max } /$ carrier number) was calculated. The difference in $V_{\max }$ between fetal and adult BBMV was reduced, but not eliminated, when the kinetics were examined in the presence of a voltage clamp. It thus is evident that the maturational increase in $V_{\max }$ is in part consequent to maturational changes in ionic conductances and membrane potential. Insofar as the $V_{\max }$ of the glucose transporter (Fig. $6 \mathrm{~B}$ ) and the number of phlorizin binding sites (Fig. 7) increased to a similar extent with development, these studies indicate that the rise in $V_{\max }$ is also, in part, consequent to the insertion of additional transporters in the brush border membrane with maturation. Note that despite the increase in $V_{\max }$, turnover number decreased with maturation (from $3.3 \mathrm{~s}^{-1}$ in fetal BBMV to $2.0 \mathrm{~s}^{-1}$ in the adult). These studies thus suggest that the developmental increase in glucose transport capacity represents the net effect of several phenomena. The insertion of additional carriers into the brush border membrane and the development of a membrane potential that is more favorable for $\mathrm{Na}^{+}$-dependent glucose transport result in an increase in $V_{\max }$. However, this increment is attenuated by a reduction in the turnover number of each carrier. Other developmental studies have also demonstrated a change in the $V_{\max }$ for solute transport during maturation. The maturational process for both taurine (28) and proline (31) transport involves an increase in $V_{\max }$. However, compared with the present study, neither of these studies determined whether the increase in $V_{\max }$ represents an increase in the numbers of carriers in the brush border consequent to increased synthesis and insertion of transporters as development proceeds and/or maturational changes in turnover rate of those carriers already present.

The present study indicates that concurrent with the increases in brush border enzyme activity and $V_{\max }$ for glucose transport, brush border membrane fluidity decreases significantly (anisotropy increases) during development (Table IV). Similar age-dependent differences in biophysical properties have been described in brush border membranes of rat kidney $(29,32,33)$ and rat (34) and rabbit (35) intestine. Such changes have been attributed to changes in membrane lipid composition and protein-lipid interactions (34). Although the functional importance of a maturational decrease in membrane fluidity remains unknown, reduced fluidity has been implicated in ontogenic differences in transport rates (29). Based on the cumulative observations in the present study, the insertion of an increased number of membrane proteins (transporters and enzymes) might possibly secondarily reduce fluidity, presumably by altering protein-lipid interactions. A maturational decrease in fluidity might also secondarily alter relative ionic conductances and/or decrease the rate of $\mathrm{Na}^{+}$gradient dissipation, thereby increasing the energy in the electrochemical potential gradient available for $\mathrm{Na}^{+}$-dependent glucose transport.

In summary, these studies demonstrate that BBMV derived from the kidney of the near-term rabbit fetus contain an $\mathrm{Na}^{+}$-dependent glucose transport system that is qualitatively indistinguishable from that in the adult. Kinetically, the fetal transporter displays the same affinity for glucose as that of the adult glucose transporter, but the maximal velocity is markedly reduced. The developmental increase in $V_{\max }$ of the glucose transporter and concurrent increase in specific activity of several brush border marker enzymes suggest that there is a significant increase in expression of both transport and enzyme activity in brush border membranes during the postnatal period. The differential increment in the specific activity of the marker enzymes further suggests that mature expression of membrane proteins (enzymes and transporters) occurs at different stages of development of renal proximal tubule cells.

\section{Acknowledgments}

This work was supported in part by grant DCB 8619421 from the National Science Foundation to Dr. Beck and DK-37315 from the National Institutes of Health to Dr. Abramson. Dr. Lipkowitz was partially supported by a National Research Service Award, DK-07117. 


\section{References}

1. Lelievre-Pegorier, M., and J. P. Geloso. 1980. Ontogeny of sugar transport in fetal rat kidney. Biol. Neonate. 38:16-24.

2. Merlet-Benichou, C., M. Pegorier, M. Muffat-Joly, and C. Augeron. 1981. Functional and morphological patterns of renal maturation in the developing guinea pig. Am. J. Physiol. 241:F618-F624.

3. Perry, J. S., and M. W. Stanier. 1962. The rate of flow of urine in foetal pig. J. Physiol. (Lond.). 161:344-350.

4. Alexander, D. P., and D. A. Nixon. 1963. Reabsorption of glucose, fructose and mesoinositol by the foetal and post-natal sheep kidney. J. Physiol. (Lond.). 167:480-486.

5. Robillard, J. E., C. Sessions, R. L. Kennedy, and F. G. Smith. 1978. Maturation of the glucose transport process by the fetal kidney. Pediatr. Res. 12:680-684.

6. Aronson, P. S., and B. Sacktor. 1975. The $\mathrm{Na}^{+}$gradient-dependent transport of D-glucose in renal brush border membranes. J. Biol. Chem. 250:6032-6039.

7. Beck, J. C., and B. Sacktor. 1975. Energetics of the $\mathrm{Na}^{+}$dependent transport of D-glucose in renal brush border membrane vesicles. J. Biol. Chem. 250:8674-8680.

8. Booth, A. G., and J. Kenny. 1974. A rapid method for the preparation of microvilli from rabbit kidney. Biochem. J. 142:575581.

9. Aronson, P. S. 1978. Energy-dependence of phlorizin binding to isolated renal microvillous membranes. J. Membr. Biol. 42:81-98.

10. Turner, R. J., and A. Moran. 1982. Heterogeneity of sodiumdependent D-glucose transport sites along the proximal tubule: evidence from vesicle studies. Am. J. Physiol. 242:F406-F414.

11. Sigma Technical Bulletin No. 104. 1982. Sigma Chemical Co. St. Louis, MO. 9-10.

12. Glossman, H., and D. M. Neville. 1972. Gamma-glutamyltransferase in kidney brush border membranes. FEBS (Fed. Eur. Biochem. Soc.) Lett. 19:340-344.

13. Goldmann, D. R., H. Schlesinger, and S. Segal. 1976. Isolation and characterization of the brush border fraction from newborn rat renal proximal tubule cells. Biochim. Biophys. Acta. 419:251-260.

14. Heidrich, H. G., R. Kinne, E. Kinne-Saffran, and K. Hannig. 1972. The polarity of the proximal tubule cell in rat kidney. Different surface charges for brush border microvilli and plasma membrane from the basal infoldings. J. Cell Biol. 54:232-245.

15. Lowry, O. H., N. J. Rosebrough, A. L. Farr, and R. J. Randall. 1951. Protein measurement with the Folin phenol reagent. J. Biol. Chem. 193:265-275.

16. Lipkowitz, M. S., and R. G. Abramson. 1987. Ionic permeabilities of rat renal cortical brush-border membrane vesicles. Am. J. Physiol. 252:F700-F711.

17. Beck, J. C., M. S. Lipkowitz, and R. G. Abramson. 1987. Developmental changes in conductive properties of rabbit renal brush border membrane vesicles (BBMV). Kidney Int. 31:429. (Abstr.)

18. Segel, I. H. 1975. Enzyme Kinetics. John Wiley \& Sons, Inc., New York, 212-214.

19. Turner, R. J., and M. Silverman. 1981. Interaction of phlorizin and sodium with the renal brush-border membrane D-glucose transporter: stoichiometry and order of binding. J. Membr. Biol. 58:43-55.

20. Scatchard, G. 1949. The attractions of proteins for small molecules and ions. Ann. NY Acad. Sci. 51:660-679.

21. Beck, J. C., and B. Sacktor. 1978. Membrane potential-sensitive fluorescence changes during $\mathrm{Na}^{+}$-dependent $\mathrm{D}$-glucose transport in renal brush border membrane vesicles. J. Biol. Chem. 253:71587162 .

22. Beck, J. C., and B. Sacktor. 1978. The sodium electrochemical potential-mediated uphill transport of D-glucose in renal brush border membrane vesicles. J. Biol. Chem. 253:5531-5535.

23. Goncharevska, O., and H. Dlouha. 1975. The development of various generations of nephrons during postnatal ontogenesis in the rat. Anat. Rec. 182:367-376.

24. Linshaw, M. A., L. W. Welling, and C. A. Bauman. 1986. Basolateral membrane properties of juxtamedullary proximal tubule in newborn rabbit. Am. J. Physiol. 251:F208-F213.

25. Lelievre-Pegorier, M., T. Jean, P. Ripoche, and P. Poujeol. 1983. Transport of phosphate, D-glucose, and L-valine in newborn rat kidney brush border. Am. J. Physiol. 245:F367-F373.

26. Goldmann, D. R., K. S. Roth, T. W. Langfitt, and S. Segal. 1979. L-Proline transport by newborn rat kidney brush border membrane vesicles. Biochem. J. 178:253-256.

27. Heinz, E., and A. M. Weinstein. 1984. The overshoot phenomenon in cotransport. Biochim. Biophys. Acta. 776:83-91.

28. Chesney, R. W., N. Gusowski, I. Zeilkovic, and M. Padilla. 1986. Developmental aspects of renal beta-amino acid transport. V. Brush border membrane transport in nursing animals: effect of age and diet. Pediatr. Res. 20:890-894.

29. Medow, M. S., and S. Segal. 1986. Age related changes in fluorescence polarization of rat brush border membrane vesicles. Biochem. Biophys. Res. Commun. 142:849-856.

30. Ghishan, F. K., and F. A. Wilson. 1985. Developmental maturation of D-glucose transport by rat jejunal brush-border membrane vesicles. Am. J. Physiol. 248:G87-G92.

31. Medow, M. S., K. S. Roth, D. R. Goldmann, K. S. Ginkinger, B. Y. L. Hsu, and S. Segal. 1986. Developmental aspects of proline transport in rat renal brush border membranes. Proc. Natl. Acad. Sci. USA. 83:7561-7564.

32. Hise, M. K., and E. J. Weinman. 1986. Physical properties of the rat renal brush border membrane during growth. Pfluegers Arch. Eur. J. Physiol. 406:234-236.

33. Chesney, R. W., N. Gusowski, and I. Zelikovic. 1987. Developmental aspects of renal beta-amino acid transport. VI. The role of membrane fluidity and phospholipid composition in the renal adaptive response in nursing animals. Pediatr. Res. 22:163-167.

34. Schwarz, S. M., B. Hostetler, S. Ling, M. Mone, and J. B. Watkins. 1985. Intestinal membrane lipid composition and fluidity during development in the rat. Am. J. Physiol. 248:G200-G207.

35. Pang, K. Y., J. L. Bresson, and W. A. Walker. 1983. Development of the gastrointestinal mucosal barrier. Evidence for structural differences in microvillous membranes from newborn and adult rabbit. Biochim. Biophys. Acta. 727:201-208. 